\title{
Feces of intertidal benthic invertebrates: influence of particle selection in feeding on trace element concentration
}

\author{
Susan L. Brown \\ Department of Oceanography, University College, Swansea SA2 8PP, United Kingdom
}

\begin{abstract}
Fecal pellets and pseudofeces of estuarine benthic infauna were analysed for cadmium copper, nickel and zinc content (using a weak acid leach and a concentrated acid leach) and compared with metal concentrations in surface sediment. Fecal pellets of the gastropod mollusc Hydrobia ulvae, and bivalve molluscs Mya arenaria, Cerastoderma edule, Scrobicularia plana and Macoma balthica contained higher metal concentrations than surface sediment samples. Average enrichment factors over sediment ranged from 1.5 to 3.6 for cadmium, 2.2 to 7.7 for copper, 1.5 to 4.0 for nickel, and 2.2 to 4.6 for zinc. Average values for metal concentrations in the polychaete Arenicola marina fecal casts were also slightly higher than sediment levels (enrichment factors of 1.2 to 1.8). Bivalve pseudofeces generally contained higher metal concentrations than surface sediment. Average enrichment factors over sediment ranged from 1.1 to 1.8 for cadmium, 1.5 to 2.6 for copper, 1.0 to 7.5 for nickel and 1.3 to 2.4 for zinc. Feces contained a larger percentage of small particles than surface sediment, particularly the bivalve fecal pellets. Metal concentrations in pooled fecal materials and sediments were inversely related to particle size and positively correlated with organic carbon content. These observations suggest that selection by animals in feeding for small particles and for organic substrates strongly influences metal concentrations in fecal materials. Since large numbers of infauna may occur in estuarine mud flats, sediment processing via fecal production by suspension feeders and selective deposit feeders is likely to be an important pathway of element cycling in estuarine ecosystems.
\end{abstract}

\section{INTRODUCTION}

The importance of organisms in the cycling of trace elements and radionuclides, via their concentration and deposition in feces, has been recognized for some time. However, investigations have focused largely on zooplankton pellets and their role as a downward transport mechanism for pollutants to the sea floor (Fowler 1977, 1982). For certain elements, fecal excretion is the major elimination route (Small et al. 1973, Small \& Fowler 1973).

Little information is available on the trace element content of fecal material of marine or estuarine benthic invertebrates. Studies on the crab Pugettia producta feeding on the brown alga Macrocystis pyrifera (Boothe \& Knauer 1972) and 5 salt marsh invertebrates (Kraeuter 1976) showed that most trace metal concentrations were generally higher in feces than in algae, halophytes or sediments. George et al. (1976) found that ferric hydroxide was accumulated to high concentrations by the mussel Mytilus edulis, but $30 \%$ of the iron presented to the gut was eliminated with the feces.

Particulates filtered by suspension feeders are deposited on the sediment in feces and pseudofeces. This process, termed biodeposition, adds new material to the sediment and may be an important pathway for the deposition of trace metals in sediments. Large quantities of detritus and sediment particles are processed by deposit-feeding infauna into fecal pellets and pseudofeces (Lee \& Swartz 1980). Any enrichment of trace elements in fecal pellets may be of consequence in the transfer of elements through food chains, since feces may constitute a quantitatively important food source (Frankenberg \& Smith 1967).

As part of a study on estuarine benthic invertebrate feces, and their role in concentrating organic matter, and regenerating nutrients during decomposition (Brown 1982), the possibility that fecal materials may be significant in the biogeochemical cycling of trace elements in estuarine ecosystems was also investigated with respect to $\mathrm{Cd}, \mathrm{Cu}, \mathrm{Ni}$ and $\mathrm{Zn}$. The concen- 
trations of these elements in biodeposits of some estuarine infauna including the mud snail (Gastropoda) Hydrobia ulvae (Pennant), the lugworm (Polychaeta) Arenicola marina (L.), and bivalve molluscs (Bivalvia), including the common cockle Cerastoderma edule (L.), the peppery furrow shell Scrobicularia plana (da Costa), the sand gaper Mya arenaria L., and the Baltic tellin Macoma balthica (L.) are reported here and compared with surface sediment (top 2 to $3 \mathrm{~mm}$ ) concentrations.

Many studies have shown that trace metal concentrations are related to particle size and organic carbon in sediments (Forstner 1979, Dossis \& Warren 1980, Thorne \& Nickless 1981) and many benthic suspension- and deposit-feeders are also known to feed selectively on a restricted range of particle sizes. Trace metal concentrations in feces were thus compared with the particle size composition (and organic carbon), to investigate the effect of particle selection in feeding on fecal metal concentrations.

\section{MATERIALS AND METHODS}

Collection of samples. Animals and samples of surface sedinent (top 2 to $3 \mathrm{~mm}$, collected with a plastic scoop), were taken during different seasons in the vicinity of Salthouse Point on the southern shore of the Loughor Estuary, South Wales. Approximately 20 Mya arenaria, 50 of each of the other bivalves, and several hundred Hydrobia ulvae were collected as soon as the receding tide uncovered the area. Shell lengths of the molluscs collected were as follows: $H$. ulvae 2.5 to $5 \mathrm{~mm}$, Cerastoderma edule 2 to $4 \mathrm{~cm}$, Scrobicularia plana 2.5 to $5 \mathrm{~cm}, M$. arenaria 7 to $10 \mathrm{~cm}$, Macoma balthica 1.5 to $2.5 \mathrm{~cm}$. Several large bowls of sediment were collected with the $H$. ulvae so that they could continue feeding in the laboratory. In sampling fresh Arenicola marina casts, an area of approximately $5 \mathrm{~m}^{2}$ was smoothed of existing casts, and fresh casts subsequently extruded were collected using a plastic knife. Sediment and animal samples were returned to the laboratory as soon as possible, and samples requiring no further treatment prior to experimental work (sediment and $A$. marina casts), were kept at $0^{\circ} \mathrm{C}$ overnight.

Preparation of animal samples for fecal pellet and pseudofeces collection. The bivalves were individually scrubbed with a nail brush to remove all sediment and organic material attached to their shells. They were then placed in collecting trays (constructed with nylon mesh glued between segments of perspex to allow pellets and pseudofecal material to fall to the bottom of the collection vessel) in bowls of $0.45 \mu \mathrm{m}$ membranefiltered seawater, and allowed to defecate. The bowls were loosely covered with plastic film to prevent pos- sible contamination. Feces and pseudofeces were removed with glass pipettes every 30 to $60 \mathrm{~min}$ and kept at $0^{\circ} \mathrm{C}$ in an incubator until sufficient material for analysis had been collected.

Hydrobia ulvae were left overnight in bowls of sediment (with a small amount of seawater) and kept in incubators set at ambient seawater temperatures. Hence they were allowed to continue feeding until the following day when time was available for pellet collection. H. ulvae were scooped up from the surface sediment and placed in nylon mesh and perspex cylinders in a beaker. They were washed thoroughly with fast-flowing tap water to remove surrounding sediment, and light pieces of organic material freed during this process were periodically decanted. Vigorous washing with tap water did not appear to adversely affect these snails as they are able to withdraw into their shells.

After washing, the snails were placed in membranefiltered seawater and allowed to move around for a short time in order to free any particles trapped in the mantle cavity when the snails withdrew into their shells during the washing process. The snails were then transferred, in their collection cylinder, into fresh filtered seawater and allowed to defecate. Pellets were removed every $30 \mathrm{~min}$ and kept at $0^{\circ} \mathrm{C}$ as for other material. When the production rate of pellets began to decline, the snails were returned to their bowls of sediment and allowed to feed again. The process was repeated until sufficient material for analysis was obtained.

Separation of fecal material from pseudofeces. Separation of fecal material from pseudofeces was achieved using nylon mesh sieves of suitable aperture size. The sieves and their contents were placed in evaporating basins filled with membrane-filtered seawater, and gently agitated to allow material smaller than the aperture size to fall through. For example, Scrobicularia plana and Cerastoderma edule samples were first passed through a $800 \mu \mathrm{m}$ aperture mesh to trap large pieces of pseudofecal material which were placed in a clean glass vial. Intact pellets were caught on a $500 \mu \mathrm{m}$ mesh and the fine pseudofecal material passed into the evaporating basin. Pellets of Macoma balthica were retained on a $170 \mu \mathrm{m}$ mesh. The pseudofecal fraction was further sorted under a low power microscope and pieces of broken fecal material were picked out with a micropipette and discarded.

Only a few greenish-brown coloured fecal pellets were produced by Mya arenaria and these were sorted manually. Two other types of ejecta were recovered from the collecting bowls: pseudofeces heavily entwined in mucus, greenish-brown in colour and rich in low density organic material; and loose unbound sand and silt grains, low in organic material and 
mucus, and sandy in colour. The loose material was expelled from the fused siphon and was not trapped between the shell valves. It was therefore thought to be unconsolidated pseudofecal material, possibly settled out within the mantle cavity prior to reaching the gills (Bernard 1974). The sticky mucilaginous pseudofeces were separated from the unbound material, and for the purpose of experimental work are described as 'mucus bound pseudofeces' and 'loose pseudofeces', respectively.

Sample preparation prior to digestion. Once sufficient material was collected, samples were washed with distilled water to remove most of the sea salts, allowed to settle and the water was carefully poured off. Samples were freeze-dried and then disaggregated and thoroughly mixed with a clean glass rod.

Chemical analysis for trace metals. Two digestion methods were used on 0.2 to $0.4 \mathrm{~g}$ each of the samples: (1) a strong boiling acid leach using a 3:1 mixture of concentrated nitric and perchloric acid that will destroy most organic matter, dissolve precipitated and adsorbed metals and dissolve most minerals except crystalline silicates (Agemian \& Chau 1976); (2) a weak acid leach using a $25 \% \mathrm{w} / \mathrm{v}$ solution of acetic acid, to provide a measure of the loosely bound fraction of trace metals (Willey 1976) that may be available for uptake into the food chain (Cranston 1974). Blanks were prepared in the same way omitting the sample. Detailed procedures of digestion techniques are given in Brown (1982).

The solutions were analysed by atomic absorption spectrophotometry (air/acetylene flame) using a Varian Techtron AA6. A calibration curve for each element was constructed daily from a range of standards made up from BDH atomic absorption standards. Blank samples (digestion mixture and double-distilled water) showed zero absorption. Non-atomic absorption was checked with a hydrogen continuum lamp. Samples and standards showed similar non-atomic absorptions which were negligible (within sample error). Coefficient of variation of 6 replicate samples ranged from 1 to $10 \%$ depending upon the element analyzed and type of digestion

All glassware and storage vessels used in trace metal analysis were soaked with concentrated nitric acid overnight, followed by thorough rinsing in doubledistilled water.

Grain size analysis by sieving. Sediment samples were freeze-dried, disaggregated in a mortar and pestle and dry sieved for $5 \mathrm{~min}$. Each fraction was then further disaggregated, recombined, weighed and returned to the bank of sieves (fraction sizes: $>500$, 315 to 500,250 to 315,160 to 250,125 to 160 , and $<63$ $\mu \mathrm{m})$, and agitated for $30 \mathrm{~min}$. Stainless steel sieves and a nylon sieve brush were employed.
A sample of sediment and 2 samples of Scrobicularia plana pseudofeces were also passed through the sieves and then recombined. Subsamples of the recombined material were analysed for metal concentrations and compared with unsieved material, to check for possible contamination during sieving; none was found.

Grain size analysis by Coulter Counter. A few $\mu \mathrm{g}$ of each sample were taken and mixed with similar sample types to provide an average or seasonal estimate of particle size distribution. Sediment, pseudofeces and feces (40 to 50 pellets of Cerastoderma edule and Scrobicularia plana and 200 pellets of Hydrobia ulvae) were dispersed in alkaline sodium hexametaphosphate followed by agitation in an ultrasonic bath for approximately $10 \mathrm{~min}$. Grain size was analysed by Coulter Counter Model TA11.

The 'relative' population of particles in the $i^{\text {th }}$ channel of the Coulter Counter $\left(P_{1}\right)$ is given by:

$$
P_{1}=\frac{\Phi_{i}}{4 / 3 \pi r_{i}^{3}}
$$

where $\Phi_{1}=$ the volume fraction (of the total particle volume) in the $i^{\text {th }}$ channel.

The relative surface area $\left(\mathrm{SA}_{\mathrm{i}}\right)$ of material in the $\mathrm{i}^{\text {th }}$ channel is given by:

$$
\begin{aligned}
& \mathrm{SA}_{\mathrm{i}}=\mathrm{P}_{\mathrm{i}} \times 4 \pi \mathrm{r}_{\mathrm{i}}^{2} \\
= & \frac{3 \Phi_{\mathrm{i}}}{\mathrm{r}_{1}}=\frac{6 \Phi_{1}}{\mathrm{~d}_{1}}
\end{aligned}
$$

where $\mathrm{d}=$ diameter of the channel.

The relative surface area for the particle sample (SA) analysed in 16 channels of the Coulter Counter is given by:

$$
\mathrm{SA}=6 \sum_{1}^{16} \frac{\Phi_{\mathrm{i}}}{\mathrm{d}_{1}}
$$

Ignoring the constant the relative surface area can be obtained from:

$$
\mathrm{SA}=\sum_{1}^{16} \frac{\Phi_{\mathrm{i}}}{\mathrm{d}_{1}}
$$

The relative surface area thus calculated should be proportional to the actual surface area. Basic assumptions are that particles are spherical and that the integrity of fecal pellet particle size diameters is reasonably constant for any batch.

Particulate organic carbon analysis. Before freeze drying, samples taken for carbon analysis were treated with $5 \%$ hydrochloric acid to remove carbonates until no effervescence occurred upon further additions of acid. Organic carbon was analysed by dry combustion. at $800^{\circ} \mathrm{C}$ in a stream of oxygen, and infra-red analysis of the carbon dioxide produced. Random checks for the 
presence of carbonate were found to be negative. Standard sucrose solutions (0 to $8,000 \mu \mathrm{g} \mathrm{C}$ ) were prepared and measured daily. Coefficient of variation for 7 to 9 replicate samples of sediment, pseudofeces and feces ranged from 2.4 to 4.9 , depending upon sample type.

A note on feeding behaviour and terminology. The distinction between suspension feeders (e.g. Cerastoderma edule, Mya arenaria) and deposit feeders (e.g. Scrobicularia plana, Macoma balthica) is not always clear, regarding the origin of ingested particles. Suspension feeders may take in some resuspended surface sediment, and some animals may display both modes of feeding, although one strategy may predominate. Except where a distinction is made between the 2 feeding types, the terms detritus feed- ers' and 'deposit feeders' are used synonymously to describe the animals investigated in this study.

\section{RESULTS}

\section{Metal concentrations in feces and sediments}

Metal concentrations found in surface sediment samples and fecal materials are given in Table 1 . All compact fecal pellets had enhanced metal levels compared with the animals' surrounding surface sediment for both acetic acid soluble fractions and nitric/perchloric digestions (Table 2). Taking the average enrichment factors for the compact fecal pellets after nitric/perchloric acid digestion, copper was concentrated to the

Table 1. Mean (range) trace metal concentrations ( $\mu \mathrm{g} \mathrm{g}^{-1} \mathrm{dry}$ wt.) in surface sediments and fecal materials. Sediment values are average of results from all sampling sites

\begin{tabular}{|c|c|c|c|c|c|c|c|c|c|}
\hline \multirow[b]{2}{*}{ Sample } & \multicolumn{4}{|c|}{ Nitric/perchloric acid digestions } & \multicolumn{4}{|c|}{ Acetic acid digestions } & \multirow{2}{*}{$\begin{array}{l}\text { No. of } \\
\text { samples }\end{array}$} \\
\hline & $\mathrm{Cd}$ & $\mathrm{Cu}$ & $\mathrm{Ni}$ & $\mathrm{Zn}$ & $\mathrm{Cd}$ & $\mathrm{Cu}$ & $\mathrm{Ni}$ & $\mathrm{Zn}$ & \\
\hline Sediment: & $\begin{array}{c}3.7 \\
(2.5-5.5)\end{array}$ & $\begin{array}{c}12.7 \\
(7.3-26.2)\end{array}$ & $\begin{array}{c}17.6 \\
(13.1-27.4)\end{array}$ & $\begin{array}{c}76.0 \\
(55.6-128.1)\end{array}$ & $\begin{array}{c}1.8 \\
(1.5-2.7)\end{array}$ & $\begin{array}{c}4.4 \\
(2.4-8.6)\end{array}$ & $\begin{array}{c}5.9 \\
(3.1-7.9)\end{array}$ & $\begin{array}{c}37.0 \\
(20.6-62.1)\end{array}$ & 26 \\
\hline$>250 \mu \mathrm{m}$ & $\begin{array}{c}10.1 \\
(6.8-13.5)\end{array}$ & $\begin{array}{c}100.1 \\
(71.0-118.0)\end{array}$ & $\begin{array}{c}37.9 \\
(26.6-50.3)\end{array}$ & $\begin{array}{c}205.9 \\
(173.6-266.7)\end{array}$ & $\begin{array}{c}4.0 \\
(1.2-5.9)\end{array}$ & $\begin{array}{c}47.7 \\
(21.3-81.6)\end{array}$ & $\begin{array}{c}13.0 \\
(6.0-17.1)\end{array}$ & $\begin{array}{c}109.5 \\
(77.6-160.9)\end{array}$ & 5 \\
\hline $160-250 \mu \mathrm{m}$ & $\begin{array}{c}4.8 \\
(3.1-7.5)\end{array}$ & $\begin{array}{c}43.7 \\
(32.6-53.0)\end{array}$ & $\begin{array}{c}34.1 \\
(25.7-51.3)\end{array}$ & $\begin{array}{c}131.9 \\
(110.1-155.0)\end{array}$ & $\begin{array}{c}2.9 \\
(2.2-3.5)\end{array}$ & $\begin{array}{c}16.3 \\
(11.8-23.4)\end{array}$ & $\begin{array}{l}10.9 \\
(8.8-13.5)\end{array}$ & $\begin{array}{c}72.1 \\
(58.9-89.0)\end{array}$ & 5 \\
\hline $125-160 \mu \mathrm{m}$ & $\begin{array}{c}4.2 \\
(2.6-6.3)\end{array}$ & $\begin{array}{c}18.7 \\
(11.8-33.4)\end{array}$ & $\begin{array}{c}17.8 \\
(14.2-29.7)\end{array}$ & $\begin{array}{c}82.5 \\
(66.0-127.2)\end{array}$ & $\begin{array}{c}1.8 \\
(1.7-1.9)\end{array}$ & $\begin{array}{c}7.6 \\
(5.0-10.1)\end{array}$ & $\begin{array}{c}6.7 \\
(5.9-7.4)\end{array}$ & $\begin{array}{c}42.9 \\
(30.8-55.2)\end{array}$ & 5 \\
\hline $90-125 \mu \mathrm{m}$ & $\begin{array}{c}3.3 \\
(2.5-4.7)\end{array}$ & $\begin{array}{l}12.1 \\
(9.6-17.4)\end{array}$ & $\begin{array}{c}13.9 \\
(11.2-19.0)\end{array}$ & $\begin{array}{c}63.8 \\
(50.4-93.0)\end{array}$ & $\begin{array}{c}1.6 \\
(1.5-1.7)\end{array}$ & $\begin{array}{c}5.3 \\
(4.1-7.9)\end{array}$ & $\begin{array}{c}5.3 \\
(4.9-6.2)\end{array}$ & $\begin{array}{c}34.2 \\
(26.7-48.2)\end{array}$ & 5 \\
\hline $63-90 \mu \mathrm{m}$ & $\begin{array}{c}4.2 \\
(3.1-6.4)\end{array}$ & $\begin{array}{c}24.1 \\
(17.7-30.0)\end{array}$ & $\begin{array}{c}22.5 \\
(19.2-27.4)\end{array}$ & $\begin{array}{c}94.6 \\
(77.5-123.7)\end{array}$ & $\begin{array}{c}2.0 \\
(1.8-2.1)\end{array}$ & $\begin{array}{c}9.5 \\
(6.7-12.0)\end{array}$ & $\begin{array}{c}6.8 \\
(5.8-7.6)\end{array}$ & $\begin{array}{c}45.4 \\
(34.3-57.7)\end{array}$ & 5 \\
\hline$<63 \mu \mathrm{m}$ & $\begin{array}{c}3.5 \\
(3.2-4.2)\end{array}$ & $\begin{array}{c}54.9 \\
(41.5-74.7)\end{array}$ & $\begin{array}{c}36.4 \\
(32.4-39.8)\end{array}$ & $\begin{array}{c}157.1 \\
(135.9-171.8)\end{array}$ & $\begin{array}{c}2.0 \\
(2.0-2.1)\end{array}$ & $\begin{array}{c}21.4 \\
(13.3-35.5)\end{array}$ & $\begin{array}{c}7.3 \\
(6.7-7.7)\end{array}$ & $\begin{array}{c}73.1 \\
(57.2-81.2)\end{array}$ & 5 \\
\hline \multicolumn{10}{|l|}{ Pseudofeces: } \\
\hline M. balthica & 3.4 & 8.1 & 12.0 & 55.8 & 1.7 & 3.8 & 4.9 & 34.2 & 1 \\
\hline C. edule & $\begin{array}{c}5.9 \\
(3.4--8.2)\end{array}$ & $\begin{array}{c}22.8 \\
(10.5-66.9)\end{array}$ & $\begin{array}{c}21.7 \\
(16.7-27.4)\end{array}$ & $\begin{array}{c}90.6 \\
(60.8-126.5)\end{array}$ & $\begin{array}{c}2.7 \\
(1.7-4.9)\end{array}$ & $\begin{array}{c}10.7 \\
(5.7-20.3)\end{array}$ & $\begin{array}{c}8.8 \\
(5.7-13.2)\end{array}$ & $\begin{array}{c}52.4 \\
(36.1-75.4)\end{array}$ & 7 \\
\hline S. plana & $\begin{array}{c}4.2 \\
(3.4-5.7)\end{array}$ & $\begin{array}{c}25.9 \\
(18.2-33.9)\end{array}$ & $\begin{array}{c}23.1 \\
(16.3-35.5)\end{array}$ & $\begin{array}{c}118.3 \\
(90.5-139.4)\end{array}$ & $\begin{array}{c}2.3 \\
(1.9-2.9)\end{array}$ & $\begin{array}{c}8.4 \\
(3.2-13.8)\end{array}$ & $\begin{array}{c}5.8 \\
(5.1-6.8)\end{array}$ & $\begin{array}{c}69.2 \\
(48.5-87.1)\end{array}$ & 6 \\
\hline \multicolumn{10}{|l|}{ M. arenaria } \\
\hline $\begin{array}{l}\text { 'Loose' } \\
\text { pseudofeces }\end{array}$ & $\begin{array}{c}3.4 \\
(2.9-3.9)\end{array}$ & $\begin{array}{c}5.3 \\
(4.7-5.8)\end{array}$ & $\begin{array}{c}12.7 \\
(12.1-13.3)\end{array}$ & $\begin{array}{c}51.5 \\
(47.3-55.6)\end{array}$ & $\begin{array}{c}1.6 \\
(1.4-1.7)\end{array}$ & $\begin{array}{c}1.9 \\
(1.3-2.4)\end{array}$ & $\begin{array}{c}5.0 \\
(4.9-5.1)\end{array}$ & $\begin{array}{c}25.0 \\
(23.5-26.5)\end{array}$ & 2 \\
\hline $\begin{array}{l}\text { 'Mucus bound' } \\
\text { pseudofeces }\end{array}$ & $\begin{array}{c}4.3 \\
(3.8-4.8)\end{array}$ & $\begin{array}{c}27.5 \\
(16.0-38.9)\end{array}$ & $\begin{array}{c}59.8 \\
(18.4-101.1)\end{array}$ & $\begin{array}{c}130.1 \\
(116.3-143.8)\end{array}$ & $\begin{array}{c}3.0 \\
(2.5-3.4)\end{array}$ & $\begin{array}{c}6.1 \\
(4.1-8.1)\end{array}$ & $\begin{array}{c}41.1 \\
(6.5-75.7)\end{array}$ & $\begin{array}{c}78.7 \\
(70.1-87.3)\end{array}$ & 2 \\
\hline \multicolumn{10}{|l|}{ Feces: } \\
\hline H. ulvae & $\begin{array}{c}8.3 \\
(5.9-10.2)\end{array}$ & $\begin{array}{c}44.1 \\
(8.4-72.4)\end{array}$ & $\begin{array}{c}30.9 \\
(23.5-41.0)\end{array}$ & $\begin{array}{c}188.2 \\
(79.7-381.4)\end{array}$ & $\begin{array}{c}3.2 \\
(2.0-5.0)\end{array}$ & $\begin{array}{l}23.4 \\
(3.8-40.3)\end{array}$ & $\begin{array}{c}11.3 \\
(9.1-16.2)\end{array}$ & $\begin{array}{c}122.6 \\
(39.6-277.0)\end{array}$ & 4 \\
\hline M. balthica & 9.8 & 40.9 & 36.4 & 205.9 & 5.5 & 17.0 & 8.7 & 137.2 & 1 \\
\hline C. edule & $\begin{array}{c}13.7 \\
(7.6-20.4)\end{array}$ & $\begin{array}{c}46.5 \\
(26.5-78.5)\end{array}$ & $\begin{array}{c}55.6 \\
(35.2-106.3)\end{array}$ & $\begin{array}{c}177.0 \\
(146.3-204.9)\end{array}$ & $\begin{array}{c}5.4 \\
(2.7-8.2)\end{array}$ & $\begin{array}{c}22.5 \\
(16.8-36.4)\end{array}$ & $\begin{array}{c}22.4 \\
(13.6-38.7)\end{array}$ & $\begin{array}{c}115.1 \\
(95.8-153.3)\end{array}$ & 7 \\
\hline S. plana & $\begin{array}{c}10.4 \\
(7.3-14.8)\end{array}$ & $\begin{array}{c}76.6 \\
(52.3-107.0)\end{array}$ & $\begin{array}{c}43.5 \\
(33.1-56.0)\end{array}$ & $\begin{array}{c}332.7 \\
(258.9-407.6)\end{array}$ & $\begin{array}{c}5.0 \\
(2.8-6.3)\end{array}$ & $\begin{array}{c}28.4 \\
(11.4-46.8)\end{array}$ & $\begin{array}{l}10.7 \\
(9.0-14.5)\end{array}$ & $\begin{array}{c}181.0 \\
(108.6-217.2)\end{array}$ & 10 \\
\hline M. arenaria & 9.1 & 37.6 & 52.9 & 233.0 & 5.5 & 12.1 & 11.1 & 99.9 & 1 \\
\hline A. marina & $\begin{array}{c}4.1 \\
(3.4-4.7)\end{array}$ & $\begin{array}{c}19.6 \\
(19.0-20.1)\end{array}$ & $\begin{array}{c}19.5 \\
(18.3-20.7)\end{array}$ & $\begin{array}{c}90.8 \\
(73.0-108.6)\end{array}$ & $\begin{array}{c}1.9 \\
(1.6-2.2)\end{array}$ & $\begin{array}{c}6.8 \\
(6.6-7.0)\end{array}$ & $\begin{array}{c}5.3 \\
(5.2-5.4)\end{array}$ & $\begin{array}{c}45.9 \\
(37.2-54.6)\end{array}$ & 2 \\
\hline
\end{tabular}


Table 2. Mean (range) enrichment factors of metal concentrations in feces and pseudofeces compared with surface sediment concentrations. $\mathrm{N} / \mathrm{P}=$ nitric/perchloric acid digestions; $\mathrm{AC}=$ acetic acid digestions. Calculated using average sediment metal levels at the animals' location. Detailed values given in Brown (1982)

\begin{tabular}{|c|c|c|c|c|c|c|c|c|c|}
\hline \multirow[b]{2}{*}{ Sample } & \multicolumn{2}{|c|}{$\mathrm{Cd}$} & \multicolumn{2}{|c|}{$\mathrm{Cu}$} & \multicolumn{2}{|c|}{$\mathrm{Ni}$} & \multicolumn{2}{|c|}{$\mathrm{Zn}$} & \multirow{2}{*}{$\begin{array}{c}\text { No. of } \\
\text { Samples }\end{array}$} \\
\hline & $N / P$ & $\mathrm{AC}$ & $\mathrm{N} / \mathrm{P}$ & $\mathrm{AC}$ & $\mathrm{N} / \mathrm{P}$ & $\mathrm{AC}$ & $N / P$ & $A C$ & \\
\hline \multicolumn{10}{|l|}{ Pseudofeces: } \\
\hline M. balthica & 0.7 & 1.1 & 1.1 & 0.9 & 0.9 & 0.8 & 1.0 & 1.1 & 1 \\
\hline C. edule & $\begin{array}{c}1.3 \\
(0.6-2.5)\end{array}$ & $\begin{array}{c}1.5 \\
(0.9-2.5)\end{array}$ & $\begin{array}{c}2.3 \\
(0.8-5.8)\end{array}$ & $\begin{array}{c}2.6 \\
(1.4-5.1)\end{array}$ & $\begin{array}{c}1.3 \\
(1.1-1.4)\end{array}$ & $\begin{array}{c}1.6 \\
(1.0-2.5)\end{array}$ & $\begin{array}{c}1.3 \\
(0.7-1.8)\end{array}$ & $\begin{array}{c}1.5 \\
(1.0-2.0)\end{array}$ & 7 \\
\hline S. plana & $\begin{array}{c}1.1 \\
(0.7-1.8)\end{array}$ & $\begin{array}{c}1.2 \\
(0.9-1.5)\end{array}$ & $\begin{array}{c}2.0 \\
(1.5-2.6)\end{array}$ & $\begin{array}{c}2.2 \\
(0.9-3.7)\end{array}$ & $\begin{array}{c}1.3 \\
(1.1-2.0)\end{array}$ & $\begin{array}{c}1.0 \\
(0.9-1.1)\end{array}$ & $\begin{array}{c}1.5 \\
(1.1-1.8)\end{array}$ & $\begin{array}{c}1.8 \\
(1.3-2.2)\end{array}$ & 6 \\
\hline \multicolumn{10}{|l|}{ M. arenaria } \\
\hline $\begin{array}{l}\text { 'Loose' } \\
\text { pseudofeces }\end{array}$ & $\begin{array}{c}1.3 \\
(0.9-1.6)\end{array}$ & $\begin{array}{c}1.0 \\
(0.9-1.0)\end{array}$ & $\begin{array}{c}0.5 \\
(0.4-0.6)\end{array}$ & $\begin{array}{c}0.4 \\
(0.3-0.5)\end{array}$ & $\begin{array}{c}0.9 \\
(0.8-1.0)\end{array}$ & $\begin{array}{c}0.8 \\
(0.7-0.9)\end{array}$ & $\begin{array}{c}0.8 \\
(0.7-0.9)\end{array}$ & $\begin{array}{c}0.8 \\
(0.7-0.8)\end{array}$ & 2 \\
\hline $\begin{array}{l}\text { 'Mucus bound' } \\
\text { pseudofeces }\end{array}$ & $\begin{array}{c}1.6 \\
(1.2-1.9)\end{array}$ & $\begin{array}{c}1.8 \\
(1.6-2.0)\end{array}$ & $\begin{array}{c}2.5 \\
(1.5-3.5)\end{array}$ & $\begin{array}{c}1.5 \\
(0.9-2.0)\end{array}$ & $\begin{array}{c}3.9 \\
(1.3-6.4)\end{array}$ & $\begin{array}{c}7.5 \\
(1.0-14.0)\end{array}$ & $\begin{array}{c}2.0 \\
(1.8-2.2)\end{array}$ & $\begin{array}{c}2.4 \\
(2.1-2.6)\end{array}$ & 2 \\
\hline \multicolumn{10}{|l|}{ Feces: } \\
\hline H. ulvae & $\begin{array}{c}2.1 \\
(1.4-2.6)\end{array}$ & $\begin{array}{c}1.9 \\
(1.0-2.9)\end{array}$ & $\begin{array}{c}3.4 \\
(1.8-8.1)\end{array}$ & $\begin{array}{c}4.1 \\
(1.3-6.8)\end{array}$ & $\begin{array}{c}1.7 \\
(1.2-2.2)\end{array}$ & $\begin{array}{c}2.3 \\
(1.4-3.1)\end{array}$ & $\begin{array}{c}2.2 \\
(1.3-3.0)\end{array}$ & $\begin{array}{c}3.1 \\
(1.4-5.0)\end{array}$ & 4 \\
\hline M. balthica & 2.0 & 3.4 & 5.6 & 3.9 & 2.6 & 1.5 & 3.4 & 4.3 & 1 \\
\hline C. edule & $\begin{array}{c}3.0 \\
(1.6-5.2)\end{array}$ & $\begin{array}{c}2.9 \\
(1.7-4.3)\end{array}$ & $\begin{array}{c}4.4 \\
(2.8-5.9)\end{array}$ & $\begin{array}{c}5.5 \\
(4.0-9.1)\end{array}$ & $\begin{array}{c}3.5 \\
(2.3-7.6)\end{array}$ & $\begin{array}{c}4.0 \\
(2.2-6.7)\end{array}$ & $\begin{array}{c}2.5 \\
(1.8-3.3)\end{array}$ & $\begin{array}{c}3.3 \\
(2.7-4.3)\end{array}$ & 7 \\
\hline S. plana & $\begin{array}{c}2.5 \\
(1.9-3.3)\end{array}$ & $\begin{array}{c}2.4 \\
(2.0-3.1)\end{array}$ & $\begin{array}{c}6.1 \\
(4.3-8.3)\end{array}$ & $\begin{array}{c}7.7 \\
(3.1-15.1)\end{array}$ & $\begin{array}{c}2.5 \\
(2.1-2.9)\end{array}$ & $\begin{array}{c}2.0 \\
(1.6-2.9)\end{array}$ & $\begin{array}{c}4.2 \\
(3.2-5.1)\end{array}$ & $\begin{array}{c}4.6 \\
(2.6-5.9)\end{array}$ & 10 \\
\hline M. arenaria & 3.6 & 3.2 & 3.6 & 2.7 & 3.8 & 1.7 & 3.7 & 2.9 & 1 \\
\hline $\begin{array}{l}\text { A. marina } \\
\text { fecal casts }\end{array}$ & $\begin{array}{c}1.2 \\
(0.8-1.6)\end{array}$ & $\begin{array}{c}1.2 \\
(0.9-1.5)\end{array}$ & $\begin{array}{c}1.8 \\
(1.4-2.1)\end{array}$ & $\begin{array}{c}1.2 \\
(1.1-1.3)\end{array}$ & $\begin{array}{c}1.2 \\
(1.0-1.4)\end{array}$ & $\begin{array}{c}1.5 \\
(1.2-1.7)\end{array}$ & $\begin{array}{c}1.4 \\
(0.9-1.9)\end{array}$ & $\begin{array}{c}1.8 \\
(0.9-2.7)\end{array}$ & 2 \\
\hline
\end{tabular}

greatest extent. In most cases, pseudofeces also contained slightly higher levels than surrounding sediment, but average enrichment factors were generally between 1.0 and 2.5. Exceptions were the Mya arenaria pseudofeces heavily coated with mucus which had higher enrichment factors for nickel, and the unbound sandy coloured $M$ arenaria pseudofeces which generally contained lower metal concentrations than surface sediment. Arenicola marina casts contained slightly higher average metal concentrations than sediment (factors of 1.2 to 1.8 ) although 4 of the 16 sample concentrations were lower (0.8 to 0.9 ).

Sediment grain sizes greater than $160 \mu \mathrm{m}$ generally contained higher metal concentrations (both digestions) than bulk sediment, in particular the fraction larger than $250 \mu \mathrm{m}$ in large pieces of organic debris such as Spartina fragments, and shell fragments that comprise the bulk of this fraction (Table 1). Except for cadmium, and loosely bound nickel, sediment fractions smaller than $125 \mu \mathrm{m}$ showed the expected relation of increasing metal levels with decreasing grain size and with organic carbon (Fig.1) and with an increasing percentage of silt $(<63 \mu \mathrm{m}$ fraction) in the sample.
The percent acetic acid extractable (PAAE) fraction, i.e. the percent of the 'total' concentration (from nitric/ perchloric acid digestions), that was extracted in $25 \%$ $\mathrm{w} / \mathrm{v}$ acetic acid, varied over a wide range, but taking average values, over half of the cadmium and zinc and over one-third of the copper and nickel were extractable in acetic acid. The PAAE fraction of nickel was the lowest of the 4 metals analysed and decreased with decreasing grain sizes $<125 \mu \mathrm{m}$ (Fig. 2a), and an inverse relation was also found with organic carbon content of sediment and sediment fractions (Fig. 2b, $\mathrm{r}=-0.90, \mathrm{p}<0.001$ ), although PAAE nickel in fecal pellets was apparently influenced by other factors. Most of the nickel particularly in the fine-grained sediment was therefore in a fraction that is not attacked by $25 \% \mathrm{w} / \mathrm{v}$ acetic acid.

\section{Particle size considerations}

Coulter Counter analysis of particle size distribution. Compact fecal pellets of the molluscs contained larger proportions of fine material than surrounding surface sediment (Fig. 3). All sediment samples tended to be 


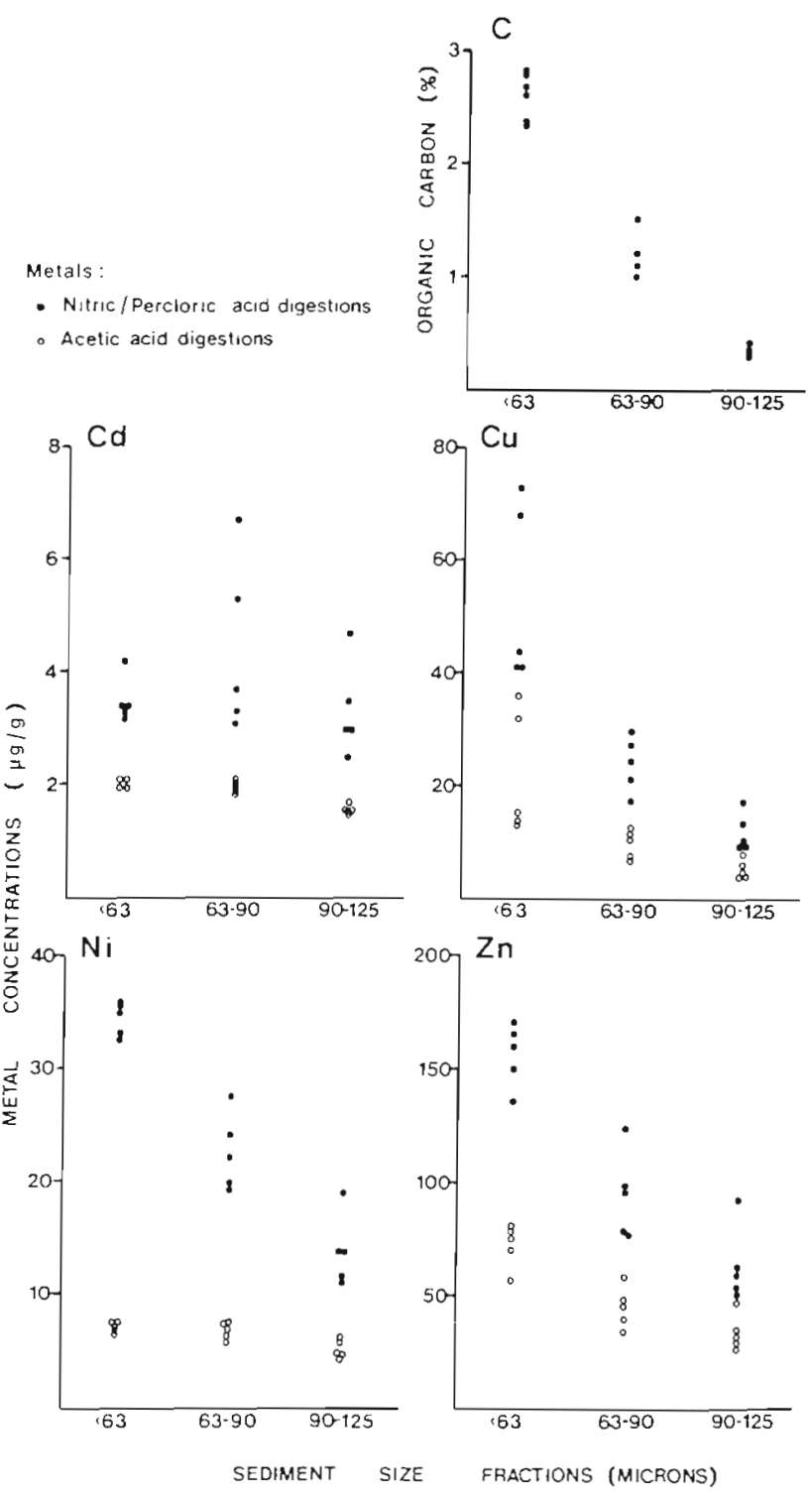

Fig. 1. Organic carbon and metal concentrations in sediment particle size fractions $<125 \mu \mathrm{m}$

negatively skewed, although to different degrees. Grain sizes in feces from Hydrobia ulvae were more evenly distributed (Fig. 3a). Particle size distribution in Cerastoderma edule and Scrobicularia plana fecal pellets (Fig. 3b, c) was positively skewed, indicating a narrower range of particle size preference for smaller sizes by the bivalves, than shown by the gastropod. The $C$. edule pseudofeces sample did not differ markedly in size distribution from the sediment while S. plana pseudofeces showed an intermediate distribution between the fecal pellet sample and the sediment samples. Both the Arenicola marina sediment and fecal samples (Fig.3d) showed a peaked, negatively skewed, distribution of grain size, however, the fecal casts contained more fine, and less coarse, material than the sediment.

\section{Correlations of metal levels with relative particle sur- face area and organic carbon}

Fecal pellet metal concentrations varied widely, however, significant and positive correlations were found between seasonally averaged concentrations of metals and relative particle surface area (Fig. 4 a to d). Loosely bound nickel showed the lowest correlation coefficient.

The trace metal concentrations of all types of samples considered together showed highly significant correlations with organic carbon content (Fig. 5 ; r values of 0.686 to $0.862, p<0.001$ ), with the exception of loosely bound nickel which gave a lower correlation coefficient ( $r=0.372, p<0.01$ ). Of the sediment samples and sediment fractions, correlations between nickel (nitric/perchloric digestions) and zinc (both digestions) with percent organic carbon in the samples were highly significant $(p<0.001)$. Analysis of correlation for copper nitric/perchloric digestions gave a significance of $\mathrm{p}<0.01$, and for cadmium, copper and nickel acetic acid digestions of $p<0.05$. No significant correlation was found between organic carbon and cadmium concentrations in sediments leached by concentrated nitric and perchloric acid.

\section{DISCUSSION}

Trace metals are accumulated by marine organisms via uptake from seawater or from food, and are eliminated via the gut in the feces, or via urine and excretion across the body surface and gills (Bryan 1971). Concentrations of elements measured in the feces are a net product of $(a)$ the amount of metals ingested that are absorbed by the animal (and which may eventually be excreted via the different pathways), (b) the proportion previously accumulated that may be excreted via the gut and incorporated with the feces, plus (c) unassimilated trace elements that were present in the undigested food.

Concentrations of trace elements are higher in fecal materials, particularly compact fecal pellets, than in surrounding sediments from which the animals select their food. An increased concentration in pellets over ingested food could not be demonstrated since the food source was not controlled, and the exact nature of material ingested was not known.

Although correlations between metals and sediment properties only describe a relation and do not identify the constituents with which a metal is associated, it has 

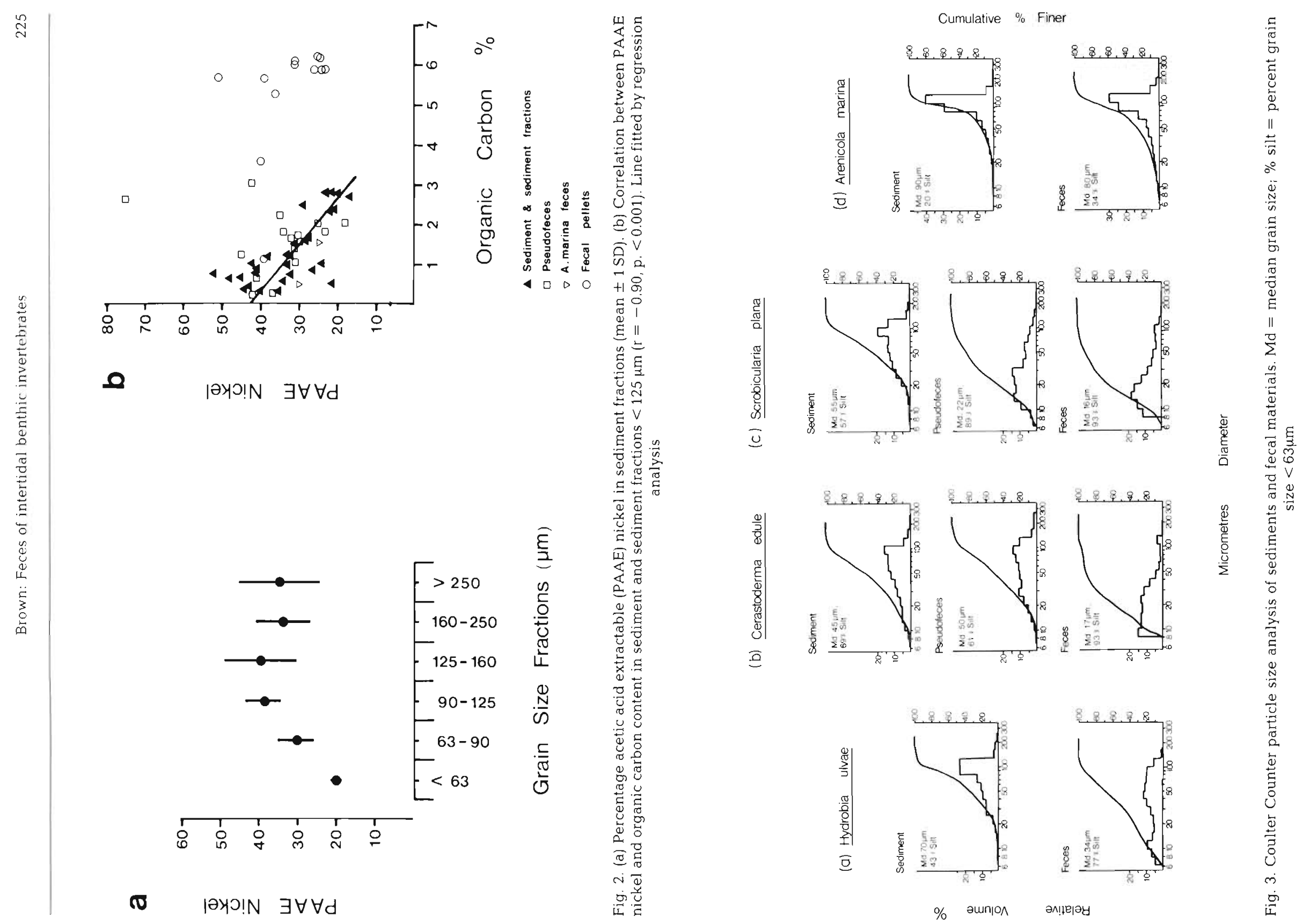


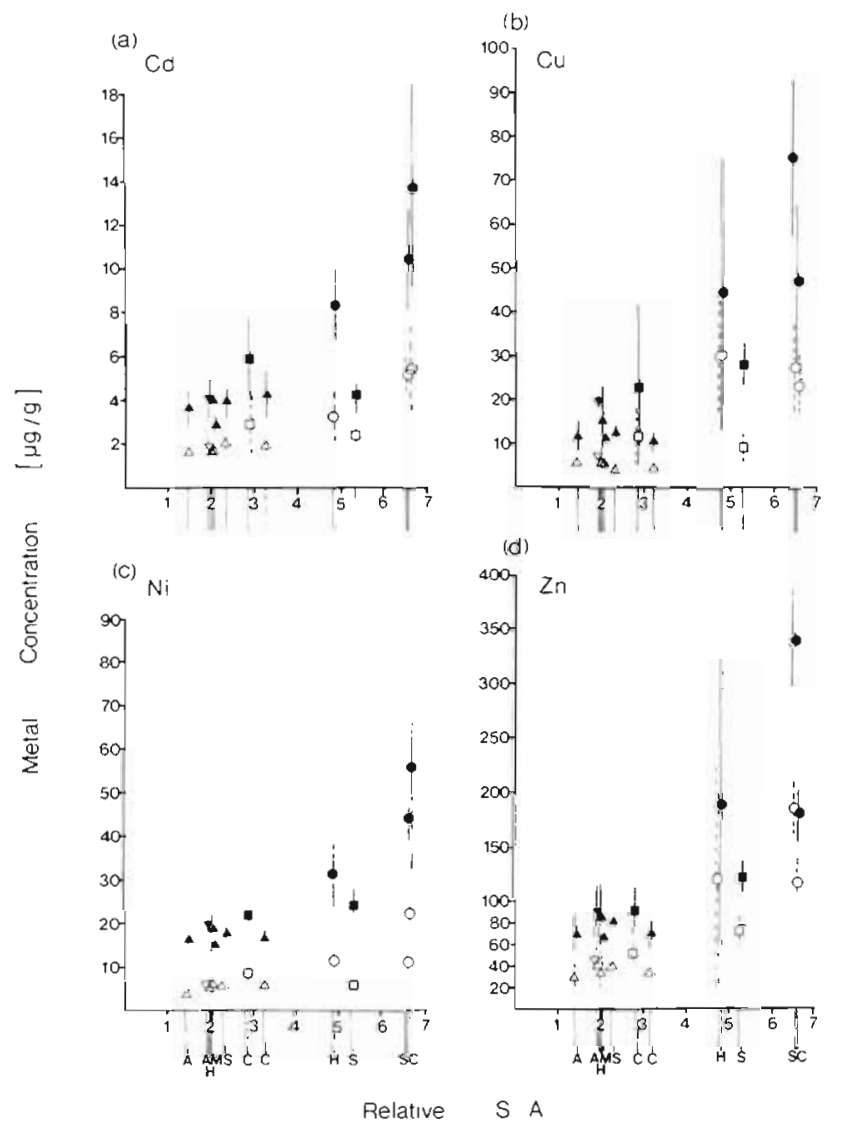

Fig. 4. Correlation between metal concentrations (mean \pm 1 SD) and relative surface area (S.A.) of sediment samples and fecal materials. A: Arenicola marina; $\mathrm{M}$ : Mya arenaria; $\mathrm{H}$ : Hydrobia ulvae; S: Scrobicularia plana; C: Cerastoderma edule. Filled symbols: nitric/perchloric acid digestions; open symbols: acetic acid digestions; $\Delta, \Delta$ : sediment; $\square, \square$ : pseudofeces; $\bullet$ O: feces; $\mathbf{\nabla}, \nabla$; A. marina fecal casts. Nitric/ perchloric acid digestions: (a) cadmium $r=0.838, p<0.01$; (b) copper $\mathrm{r}=0.867, \mathrm{p}<0.001$; (c) nickel $\mathrm{r}=0.876, \mathrm{p}<0.001$; (d) zinc $\mathrm{r}=0.816, \mathrm{p}<0.01$ Acetic acid digestions: (a) cadmium $r=0.882, p<0.001$; (b) copper $r=0.800, p<0.01$; (c) nickel $\mathrm{r}=0.751, \mathrm{p}<0.01 ;$ (d) zinc $\mathrm{r}=0.879, \mathrm{p}<0.001$

been established that, in general, higher trace metal concentrations are encountered in the finer-grained, organic rich portions of the sediment in the area of the present investigation. Since this is the fraction selected by many deposit feeders, these animals are exposed to higher metal levels than indicated by average concentrations in bulk sediment. Of the 4 metals analyzed this would not apply for loosely-bound nickel since the 'available' fraction of this element decreased with organic carbon content and decreasing grain size. Vivian (1976) also noted that in Swansea Bay, adjacent to the present study site, the percent acetic acid extractable fraction was also inversely related to organic carbon and silt content.

Other studies with salt marsh invertebrates have shown an enrichment of trace metals in feces com-

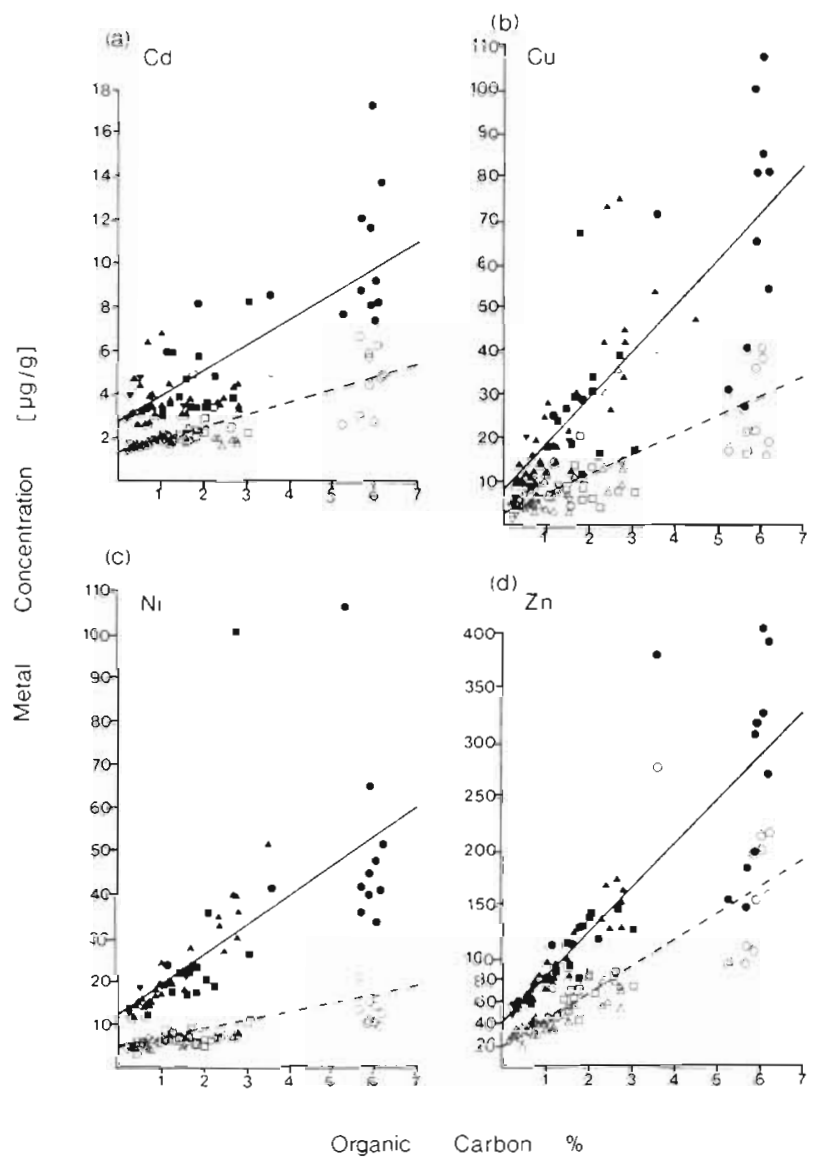

Fig. 5. Correlations between metal concentrations and organic carbon content. Filled symbols: nitric/perchloric acid digestions; open symbols: acetic acid digestions; $\Delta, \Delta$ : sediment samples and sediment fractions; $\bullet$, f fecal pellets; $\boldsymbol{\nabla}, \nabla$ : Arenicola marina fecal casts and $M y a$ arenaria loose pseudofeces; $\boldsymbol{\bullet},[]$ : pseudofeces including $M$. arenaria mucusbound pseudofeces. Nitric/perchloric acid digestions: (a) cadmium $\mathrm{r}=0.716, \mathrm{p}<0.001$; (b) copper $r=0.792, \mathrm{p}<0.001$; (c) nickel $r=0.686, p<0.001$; (d) zinc $r=0.862, p<0.001$ (60 samples). Acetic acid digestions: (a) cadmium $r=0.810$, $p<0.001$; (b) copper $r=0.753, p<0.001$; (c) nickel $r=0.372$, $\mathrm{p}<0.01$; (d) zinc $\mathrm{r}=0.834, \mathrm{p}<0.001$ (60 samples). Lines fitted by regression analyses

pared with surface sediment and/or food substrate (Kraeuter 1976). Boothe \& Knauer (1972) measured the concentrations of 9 trace elements in the feces of the crab Pugettia producta, and in the brown alga Macrocystis pyrifera on which the crab was fed. Seven of the elements were concentrated in the feces above levels in food, including zinc and copper, but this feature was not found for cadmium. This contrasts with studies on euphausiids (Benayoun et al. 1974) where cadmium was found to be excreted largely in the feces.

Assimilation of organic material reduces the volume between ingestion and egestion and concentrates 'non-available' metals. Therefore for animals with high assimilation efficiencies, the concentration of ele- 
ments in the feces may be largely due to the reduction in the weight of food egested compared with ingested food. This assumes that trace elements are not all available for uptake and are not assimilated in the same proportion as the food. In the experiments of Boothe \& Knauer (1972) metal concentrations in crab feces were higher than in the alga, but not as high as the theoretical maximum (algal metal concentration $x$ weight ratio of algae consumed to feces egested) due to absorption across the gut and subsequent excretion via other routes. In sediment-ingesting infauna a large amount of inorganic material is ingested with various sources of organic material. Over $95 \%$ of the dry weight of material ingested by Scrobicularia plana is inorganic material (Hughes 1969). For deposit feeders then, assimilating only a small percentage of material passing through their guts, the reduction in weight between ingested and egested material is unlikely to contribute significantly to higher fecal metal concentrations. A large proportion of sediment-bound trace elements such as the fraction insoluble in $25 \% \mathrm{w} / \mathrm{v}$ acetic acid will be unavailable for assimilation and will be directly egested. Cross et al. (1975) found that because assimilation efficiencies for trace metals ingested by juvenile estuarine fish were low, most of the metals ingested were egested in the feces. The concentrations of trace metals in feces of estuarine deposit feeders are likely therefore to reflect the concentrations in ingested material. Hence the selection of materials prior to ingestion for fine particle size and for organic material must be a major influence on fecal pellet trace metal levels in sediment ingesting organisms.

Sieving of sediment samples for trace metal analysis of the different fractions in the present study indicated that, in general, the largest percentage (by weight) of the samples was composed of 2 size fractions between 90 and $160 \mu \mathrm{m}$. The sediment samples analysed by Coulter Counter exhibited a peak (in \% volume) between about 80 and $160 \mu \mathrm{m}$. Many deposit feeders, however, ingest particles of a predominantly smaller size range. This is seen clearly from the results of the Coulter Counter analyses (Fig. 3). Fenchel et al. (1975) noted that Hydrobia ulvae can ingest particles of size ranging between $20 \mu \mathrm{m}$ and 200 to $300 \mu \mathrm{m}$, but will select for particular diatom sizes (depending upon snail size) and will browse on surfaces of large particles. In the present study, some selection was evident and can be further explained by observations of Lopez \& Kofoed (1980) who found that although $H$. ulvae can ingest particles up to $200 \mu \mathrm{m}$, snails ( 4 to $4.5 \mathrm{~mm}$ long) fed most rapidly upon particles $40 \mu \mathrm{m}$ and 40 to $80 \mu \mathrm{m}$. Feeding rate decreased with increasing particle size, and on 80 to $160 \mu \mathrm{m}$ sediments the rate was one-third of that on 40 to $80 \mu \mathrm{m}$ sediments. In the feces from Scrobicularia plana and Cerastoderma edule (Fig. 3b, c) approximately $80 \%$ (by volume) of the constituent particles were smaller than $30 \mu \mathrm{m}$, and the sediment contained only 20 to $30 \%$ of particles below this size.

Sediment particles in the fraction $<30 \mu \mathrm{m}$ were not analyzed separately for their metal content in the present study. However, enrichment factors of the fraction $<63 \mu \mathrm{m}$ over bulk sediment (Table 3) show increased concentrations in this fraction (e.g. up to a 7 -fold increase for copper), and this suggests this is a major reason for the similar increase seen for copper in feces compared with bulk sediment. Cadmium was only slightly higher in the $<63 \mu \mathrm{m}$ fraction than in bulk sediment and does not explain the increase in fecal pellets. It is possible that cadmium that has accumulated from pathways other than food is excreted with the feces. Alternatively, cadmium may be associated with a fraction considerably smaller than $63 \mu \mathrm{m}$ whose distribution is not revealed within the limits of size separation here.

Since organic carbon levels are related to grain size, correlations with organic material can be secondary (Jones \& Jordan 1979). However, metals can bind to organic material and the considerable quantity of organic matter present in coastal sediments tends to coat silt and clay particles, and probably reduces direct adsorption by clay minerals (Meyers \& Quinn 1974). Metals may be accumulated by algae and also marsh grasses (Williams \& Murdoch 1969, Drifmeyer et al. 1982) and may be further concentrated as marsh vegetation is broken down to detritus (Lindberg et al. 1975 , Rice \& Windom 1982). In the present study, higher metal concentrations than bulk sediment were found

Table 3. Metal enrichment factors of sediment size fraction $<63 \mu \mathrm{m}$ over bulk surface sediment concentration. Mean (range) value of 5 samples

\begin{tabular}{|cccccc}
\hline & $\mathrm{Cd}$ & $\mathrm{Cu}$ & $\mathrm{Ni}$ & $\mathrm{Zn}$ \\
\hline & 1.13 & 4.15 & 2.02 & 1.96 \\
Nitric/perchloric & $(0.89-1.68)$ & $(1.60-7.18)$ & $(1.34-2.84)$ & $(1.29-2.70)$ \\
acid digestions & 1.14 & 4.39 & 1.16 & 1.85 \\
Acetic acid digestions & $(0.99-1.19)$ & $(1.60-7.89)$ & $(0.99-1.21)$ & $(1.17-2.37)$ \\
\end{tabular}


in the fraction $>250 \mu \mathrm{m}$ which contained pieces of organic debris such as Spartina fragments that are a major source of organic material to salt marsh flats. Further, metal concentrations in detritus, being lighter than quartz grains, will be enhanced relative to other smaller size fractions since levels are expressed on a weight basis.

Particle selection by animals on a density basis, for organic substrates, will influence trace element concentrations in feces and pseudofeces and modify levels expected from considerations of grain size alone. The particles in the pseudofeces may not differ markedly in size from bulk sediment, but pseudofeces appear to contain a greater proportion of low density organic debris. It has been assumed that the intake of particles at the tip of the siphon is probably unselective in some deposit-feeding bivalves (Hylleberg \& Gallucci 1975). However, a degree of physical, or 'hydraulic' sorting may occur, with a larger proportion of lighter material being taken into the siphon, leaving denser grains on the sediment surface.

In the present study, fecal pellets contained higher organic carbon content and higher metal levels than sediment, but exhibited a wide range of metal concentrations over a narrower range of organic carbon (Fig.5). This probably reflects the heterogeneous nature of organic material and seasonal differences in the food supply (e.g. phytoplankton/benthic diatoms:organic detritus ratio) and changes in metal levels which may occur during passage through the gut of an organism. Loosely bound metals, extractable in $25 \% \mathrm{w} / \mathrm{v}$ acetic acid, are potentially available for uptake, and this fraction was variable but significant in the samples analyzed in the present study, particularly for copper and zinc (averaging over $50 \%$ ). Some may be assimilated from ingested food and this would decrease levels egested with the feces. Conversely, some trace metals that have accumulated in an organism from other pathways (e.g. via solution) may be eliminated via the gut in particulate form or adsorbed onto the feces, thus increasing fecal metal levels.

Elimination via the gut may be an important pathway in organisms such as crustaceans (Bernard \& Lane 1961, Bryan 1968, Renfro et al. 1974) and molluscs (Potts \& Todd 1965). In Cerastoderma edule, metals are excreted in spheres pinched off from the digestive cells (Owen 1955). Presumably these may be carried back to the gut and included in the feces.

Scott \& Major (1972) suggested that copper levels in Mytilus edulis may be controlled by removal with the feces and/or with mucus secreted from the gills. When animals were placed in seawater with $0.3 \mathrm{mgl}^{-1} \mathrm{cop}$ per, an increase in mucus production was observed. Metals may be taken up by ion exchange onto mucus secreted by body surfaces, particularly the mantle and gills (Pringle et al. 1968, Pentreath 1973) and may be exported to the gut or expelled with the pseudofeces. A concentration of trace metals in mucus substances expelled with the pseudofeces may contribute to the relatively higher concentrations found in pseudofeces (Table 2), particularly the mucilaginous material produced by Mya arenaria. Mucus sheets on oyster gills have been shown to concentrate trace metals (Korringa 1952, Brooks \& Rumsby 1965) and Harrison (1972, 1973) found ${ }^{65} \mathrm{Zn},{ }^{60} \mathrm{Co}$ and ${ }^{137} \mathrm{Cs}$ were concentrated in the mucopolysaccharide/proteinaceous 'peel' covering the siphons and mantle margin of Mya arenaria.

The relative importance of these processes on fecal metal concentrations was not determined in the present study on fecal materials produced from natural food sources. Natural sediments comprise a heterogeneous mixture of inorganic and organic particles with a complexity of metal associations. Controlled experiments, with a more homogeneous food source of particles that are acceptable for ingestion and/or tracer studies, should help to determine the relative contributions of particle selection and net transfer of metals during passage through the animals to fecal concentrations. More reliable estimates of particle surface area may be obtained by methods other than Coulter Counter analysis, although alternative methods such as nitrogen sorption require larger samples than those available in the present study.

Few data exist for trace element concentrations in animals from the Loughor Estuary used in the present study (Table 4), however, concentrations in fecal pellets measured in the present study are similar or higher than these whole animal and individual tissue concentrations. It is likely that levels in fecal pellets are higher than those in tissues of animals near Salthouse Point, since the data on Scrobicularia plana (Table 4) are from animals collected on the north side of the Estuary, in the proximity of major industrial sewage and river discharges. Metal levels in sediments and water in this area are higher than those measured in the present study (Smith unpubl. 1978, Wright 1978). The probability that metal levels in feces are higher than in animals supports the conclusion of Flegal \& Martin (1977) and Hall \& Merlini (1979), that deposit feeding animals should be allowed to completely empty their guts before they are analyzed for metal concentrations, since errors from contamination with ingested sediment may be considerable.

Fecal material is considered to play a role in trophic relations of coastal benthic communities (Frankenberg et al. 1967) and comprise excellent substrates for microbial growth (Hargrave 1976). The present study shows that coprophagous species may be subject to preconcentrated metal levels. Little is known concerning the effects of residual digestive enzymes on metals 
Table 4. Metal concentrations in bivalves from the Loughor Estuary

\begin{tabular}{|c|c|c|c|c|}
\hline & \multicolumn{4}{|c|}{ Metal concentrations ( $\left.\mu \mathrm{g} \mathrm{g}^{-1} \mathrm{~d} r y \mathrm{wt}\right)$} \\
\hline & $\mathrm{Cd}$ & $\mathrm{Cu}$ & $\mathrm{Ni}$ & $\mathrm{Zn}$ \\
\hline $\begin{array}{l}\text { C. edule, whole animals, } \\
\text { from } 2 \text { sites (exact location unknown) } \\
\text { (Wright 1978) }\end{array}$ & $\begin{array}{c}1.1 \\
(0.9-1.3)\end{array}$ & $\begin{array}{c}14.2 \\
(12.8-15.2)\end{array}$ & $\begin{array}{c}37 \\
(35-39)\end{array}$ & $\begin{array}{c}154 \\
(138-171)\end{array}$ \\
\hline $\begin{array}{l}\text { S. plana, whole animals, } \\
\text { Trostre } \\
\text { Machynys Point } \\
\text { (Smith pers. comm.) }\end{array}$ & $\begin{array}{c}1.8-1.9 \\
2\end{array}$ & $\begin{array}{c}28-42 \\
26\end{array}$ & $\begin{array}{c}3-5 \\
-\end{array}$ & $\begin{array}{l}627-678 \\
394\end{array}$ \\
\hline $\begin{array}{l}\text { C. edule, soft tissue, Machynys Point } \\
\text { (Wigham 1977) }\end{array}$ & $1.76 \pm 0.2$ & $7.61 \pm 1.8$ & - & $97.1 \pm 17.3$ \\
\hline $\begin{array}{l}\text { S. plana, soft tissue, Machynys Point } \\
\text { (Wigham 1977) }\end{array}$ & $2.27 \pm 0.5$ & $25.82 \pm 7.3$ & - & $394.7 \pm 106.4$ \\
\hline
\end{tabular}

that are passed out with the feces, or the effects of decomposition on the fate of trace elements in feces. Such studies would elucidate the role of benthic detritus feeders in the cycling of metals between dissolved and particulate phases. Possible pathways are: leaching during the decomposition of organic matter (return to solution), or transfer into microorganisms such as bacteria and diatoms that colonize fecal pellets and uptake by coprophagous species, or by deposit feeders following pellet breakdown. Uptake by microflora may render metals more 'available' than sediment-bound metals to detritus-feeding organisms and may be an important mechanism for the transfer of heavy metals from sediments to the macrofauna. Such a process may be particularly important in decomposing fecal pellets which have initially high trace element levels, and potential for heavy microbial colonization.

Feces and pseudofeces usually exhibit different hydrodynamic properties from surface sediment grains. After fecal pellets are voided they may not remain close to the site of production, but they may be transported with the bedload or entrained into suspension (Risk \& Moffat 1977, Nowell et al. 1981), depending upon pellet type, turbulence and current velocities. Observations in a seawater laboratory flume (Brown 1982) indicated that the cylindrical pellets of Cerastoderma edule and Scrobicularia plana have a lower critical erosion velocity than untransformed sediment and were transported along the sediment surface faster than sediment bedload movement. The presence of Hydrobia ulvae pellets in seawater samples, collected from $1 \mathrm{~m}$ above the sediment surface, demonstrated that these pellets may be carried in suspension. Significant quantities of fecal pellets have been observed in suspension in some estuaries (Haven \& MoralesAlamo 1968) and where this is the case, fecal pellets may represent an important pathway for the lateral movement of trace elements, e.g. from estuaries into coastal waters.

In summary, biodeposits of detritus-feeding infauna contain elevated concentrations of trace metals compared with surface sediments. This is largely a result of particle selection in feeding. The activities of suspension feeders will accelerate the deposition of trace metals in surface sediments. The activities of selective deposit feeders that eject feces at the surface maintain these element-rich particulates in the sediment water interface. Here microbial activity is high and exchange of dissolved substances takes place. Bioturbation may also enhance resuspension of the pelletized surface and the exchange of materials between sediment and the overlying water. In view of the high abundance of infauna that may occur in estuarine mud flats, and high reworking rates, feces of deposit feeders and suspension feeders are likely to constitute an important pathway in the flux of trace elements between the components of the estuarine ecosystem.

Acknowledgements. I thank S. W. Fowler, B. T. Hargrave, S. R. Aston and R. Bryant for critically reviewing the manuscript. I am also grateful to F. T. Banner, K. S. Massie and S. J. Wakefield for their advice and provision of research facilities at the Oceanography Department, University College of Swansea. Thanks are also due to J. D. Burton and P. LeB. Williams for allowing me the use of the carbon analyzer in the Department of Oceanography, Southampton University; and J. Greengo of the Oceanography Department, University College of Swansea, for typing the manuscript. Support for the research was funded by a postgraduate scholarship awarded by the University of Wales.

\section{LITERATURE CITED}

Agemian, H., Chau, A. S. Y. (1976). Evaluation of extraction techniques for the determination of metals in aquatic sediments. The Analyst 101 (1207): 761-767 
Benayoun, G., Fowler, S. W., Oregioni, B. (1974). Flux of cadmium through euphausidds. Mar. Biol. 27: 205-212

Bernard, F. R. (1974). Particle sorting and labial palp function in the Pacific oyster Crassostrea gigas (Thunberg, 1975). Biol. Bull. mar. biol. Lab., Woods Hole 146: 1-10

Bernard, F. T., Lane, C. E. (1961). Absorption and excretion of copper ion during settlement and metamorphosis of the barnacle Balanus amphitrite niveus. Biol. Bull. mar. biol. Lab. Woods Hole 121: 448-450

Boothe, P. N., Knauer, G. A. (1972). The possible importance of faecal material in the biological amplification of trace and heavy metals. Limnol. Oceanogr. 17: 270-274

Brooks, R. R., Rumsby, M. G. (1965). The biogeochemistry of trace element uptake by some New Zealand bivalves. Limnol. Oceanogr. 10: 521-527

Brown, S. L. (1982). Estuarine benthic invertebrate faeces: observations on decomposition and on aspects of chemical cycling. Ph. D. thesis, Univ. of Wales, Swansea

Bryan, G. W. (1968). Concentrations of zinc and copper in the tissues of decapod crustaceans. J. mar. biol. Ass. U.K. 48: 303-321

Bryan, G. W. (1971). The effects of heavy metals (other than mercury) on marine and estuarine organisms. Proc. R. Soc. (B) $177: 389-410$

Cranston, R. E. (1974). Geochemical interaction in the recently industrialized Strait of Canso. Proc. Int. Conf. Transport of Persistent Chemicals in Aquatic Ecosystems, Ottawa, Canada 1: 59-67

Cross, F. A., Willis, J. N., Hardy, L. H., Jones, N. Y., Lewis, J. M. (1975). Role of juvenile fish in cycling of $\mathrm{Mn}, \mathrm{Fe}, \mathrm{Cu}$ and $\mathrm{Zn}$ in a coastal-plain estuary. In: Cronin, L. E. (ed.) Estuarine research. Vol. 1. Academic Press, New York, p. $45-63$

Dossis, P., Warren, L. J. (1980). Distribution of heavy metals between the minerals and organic debris in a contaminated marine sediment. In: Baker, R. A. (ed.) Contaminants and sediments. Vol. 1. Ann Arbor Science, Michigan, p. 119-139

Drifmeyer, J. E., Cross, F. A., Zieman, J. C. (1982). Sorption and desorption of trace elements by Spartina alterniflora detritus. Plant and Soil 66: 69-80

Fenchel, T., Kofoed, L. H., Lappalainen, A. (1975). Particle size selection of two deposit feeders, the amphipod Corophium volutator and the prosobranch Hydrobia ulvae. Mar. Biol. 30: 119-128

Flegal, A. R., Martin, J. H. (1977). Contamination of biological samples by ingested sediment. Mar. Pollut. Bull., N.S. 8: 90-92

Forstner, U. (1979). Metal transfer between solid and aqueous phases. In: Forstner, U., Wittman, G. T. W. (ed.) Metal pollution in the aquatic environment. Springer, Berlin, Heidelberg, New York, p. 197-270

Fowler, S. W. (1977). Trace elements in zooplankton particulate products. Nature, Lond. 269: 51-53

Fowler, S. W. (1982). Biological transfer and transport proces ses. In: Kullenberg, G. (ed.) Pollutant transfer and transport in the sea. Vol. II. CRC Press, Inc., Boca Raton, Florida, p. 1-65

Frankenberg, D., Coles, S. L., Johannes, R. E. (1967). The potential trophic significance of Callianassa major faecal pellets. Limnol. Oceanogr. 12: 113-120

Frankenberg, D., Smith, K. L. (1967). Coprophagy in marine animals. Limnol. Oceanogr 12: 443-450

George, S. G., Pirie, B. J. S., Coombs, T. L. (1976). The kinetics of accumulation and excretion of ferric hydroxide in $M$. edulis (L.) and its distribution in the tissues. J. exp. mar. Biol. Ecol. 23: 71-84
Hall, T. M., Merlini, L. (1979). An attempt to determine the influence of the gut content on the determination of heavy metals in aquatic oligochaetes. Memorie Ist. ital. Idrobiol. 37: $33-40$

Hargrave, B. T (1976). The central role of invertebrate faeces in sediment decomposition. In: Anderson, J. M., Macfayden, A. (ed.) The role of terrestrial and aquatic organisms in decomposition processes. Blackwell Scientific Publications, Oxford, p. 301-321

Harrison, F. L. (1972). Accumulation and loss of zinc by the marine clam Mya arenaria. Abstract P/12. 17th Annual Mtg. of the Health Phys. Soc., June 11-15. Las Vegas, Nevada

Harrison, F. L. (1973). Accumulation and loss of cobalt and caesium by the marine clam Mya arenaria, under laboratory and field conditions. In: Radioactive contamination of the marine environment. IAEA, Vienna, p. 453-478

Haven, D. S., Morales-Alamo, R. (1968). Occurrence and transport of faecal pellets in suspension in a tidal estuary. J. sed. Geol. 2: 141-151

Hughes, R. N. (1969). A study of feeding in Scrobicularia plana. J. mar. biol. Ass. U.K. 49: 805-823

Hylleberg, J., Gallucci, V. F. (1975). Selectivity in feeding by the deposit feeding bivalve Macoma nasuta. Mar. Biol. 32: $167-178$

Jones, G. B., Jordan, M. B. (1979). The distribution of organic material and trace metals in sediments from the River Leffey estuary. Dublin. Estuar. coast. mar. Sci. 8: 37-47

Korringa, P. (1952). Recent advances in oyster biology. Q. Rev. Biol. 27: 339-365

Kraeuter, J. N. (1976). Biodeposition by salt-marsh invertebrates. Mar. Biol. 35: 215-223

Lee, H., Swartz, R. C. (1980). Biological processes affecting the distribution of pollutants in marine sediments. Part II. Biodeposition and bioturbation. In: Baker, R. A. (ed.) Contaminants and sediments. Vol. 2. Analysis, Chemistry, Biology. Ann Arbor Science, Michigan, p. 555-606

Lindberg, S. E., Andren, A. W., Harriss, C. (1975). Geochemistry of mercury in the estuarine environment. In: Cronin, L. E. (ed.). Estuarine research, Vol. 1. Academic Press, New York, p. 64-107

Lopez, G. R., Kofoed, L. H. (1980). Epipsammic browsing and deposit-feeding in mud snails (Hydrobiidae). J. mar. Res. 38: 585-599

Meyers, P. A. Quinn, J. G. (1974). Organic matter on clay minerals and marine sediments - effect on adsorption of dissolved copper, phosphate and lipids from saline solutions. Chem. Geol. 13: 63-68

Nowell, A. R., Jumars, P. A., Eckman, J. E. (1981). Effects of biological activity on the entrainment of marine sediments. Mar. Geol. 42: 133-153

Owen, G. (1955). Observations on the stomach and digestive diverticula of the Lamellibranchia. I. The Anisomyana and Eulamellibranchia. Q. J. microsc. Sci. 96: 517-537

Pentreath, R. J. (1973). The accumulation from water of ${ }^{65} \mathrm{Zn}$ ${ }^{54} \mathrm{Mn},{ }^{58} \mathrm{Co}$ and ${ }^{59} \mathrm{Fe}$ by Mytilus edulis. J. mar. biol. Ass U.K. 53: $127-143$

Potts, W T. W., Todd, M. (1965). Kidney function in the octopus. Comp. Biochem. Physiol. 16: 479-489

Pringle, B. H., Hissong, D. E., Katz, E. L., Mulawka, S. T (1968). Trace metal accumulation by estuarine molluscs. J Sanit. Engng Div. Am. Soc. Civ. Engrs SA3, 94: 455-475

Renfro, W C., Fowler, S. W., Heyraud, M., La Rosa, J. (1974) Relative importance of food and water pathways in the bio-accumulation of ${ }^{65} \mathrm{Zn}$. In: Activities of the International Laboratory of Marine Radioactivity, 1974 Report Technical Report IAEA-163, IAEA, Vienna, p. 11-20 
Rice, D. L., Windom, H. L. (1982). Trace metal transfer associated with the decomposition of detritus from estuarine macrophytes. Botanica mar. 25: 213-223

Risk, M. J., Moffat, J. S. (1977). Sedimentological significance of faecal pellets of Macoma balthica in the Minas Basin, Bay of Fundy. J. sedim. Petrol. 47: 1425-1436

Scott, D. M., Major, C. W. (1972). The effect of copper (II) on survival, respiration and heart rate in the common blue mussel, Mytilus edulis. Biol. Bull. mar. biol. Lab., Woods Hole 143: 679-688

Small, L. F., Fowler, S. W. (1973). Turnover and vertical transport of zinc by the euphausiid Meganyctiphanes norvegica in the Ligurian Sea. Mar. Biol. 18: 284-290

Small, L. F., Fowler, S. W., Keckes, S. (1973). Flux of zinc through a macroplanktonic crustacean. In: Radioactive contamination of the marine environment. IAEA, Vienna, p. $437-452$

Thorne, L. T., Nickless, G. (1981). The relation between heavy metals and particle size fractions within the Severn Estu- ary (U.K.) intertidal sediments. Sci. Total Environ. 19 (3): $207-213$

Vivian, C. M. G. (1976). Trace metals in Swansea Bay. Ph. D. thesis. Univ. of Wales, Swansea

Wigham, G. D. (1977). Heavy metal loads of Bristol Channel biota. In: Nelson-Smith, A., Bridges, E. M. (ed.) Problems of a small estuary, Quadrant Press Ltd., Swansea, p. 3: $3 /$ 1-3: $3 / 14$

Willey, J. D. (1976). Geochemistry and environmental implications of the surficial sediments in northern Placentia Bay, Newfoundland. Can. J. Earth Sci. 13: 1393-1410

Williams, R. B., Murdoch, M. B. (1969). The potential importance of Spartina alterniflora in conveying zinc, manganese and iron into estuarine food chains. In: Nelson, D. J., Evans, F. D. (ed.) Symposium on radioecology. U.S. Atomic Energy Commission, p. 431-439

Wright, D. (1978). Trace metal studies in the Loughor Estuary. Ph. D. thesis. Univ. of Liverpool

This paper was presented by Dr. G. W. Bryan; it was accepted for printing on October 24, 1985 